\title{
The Nightingale Prize for best MBEC paper in 2011
}

\author{
Jos A. E. Spaan
}

Received: 31 October 2012/Accepted: 1 November 2012/Published online: 25 November 2012

(C) International Federation for Medical and Biological Engineering 2012

The Nightingale Prize is named after Alfred Nightingale who was the first Editor in Chief of Medical and Biological Engineering and Computing, MBEC. He died in 1963 at the age of 40 [17]. He was a promising scientist and pioneer in the field of electromyography [14]. The prize was established in cooperation between the Institute of Physics and Engineering in Medicine ${ }^{1}$ and the International Federation of Medical and Biological Engineering ${ }^{2}$.

Since biomedical engineering papers do not collect citations so fast to allow citation frequency to be used as a selection criterion [12, 18] and the Nightingale prize is intended to recognize a recent paper an alternative procedure was established. The manuscripts that received a priority of $90 \%$ or higher from the reviewers were selected with the exclusion of reviews and original papers with a rather senior author. The final list consisted out of 10 papers that will be recognized by this editorial.

The selected winning paper of this year is by Sigal Portnoy, Nicolas Vuillerme, Yohan Payan and Amit Gefen from the department of Biomedical Engineering, Tel Aviv University, Israel. The paper is entitled "Clinically oriented real-time monitoring of the individual's risk for deep tissue injury" [13]. This is one of the rare submissions where both reviewers not only gave a high score but recommended accept after first reading. The study aimed to formulate a patient-specific biomechanical model that can help in the continuously monitoring of internal tissue stresses in real time based on surface pressure data obtained form paraplegic patients in a wheelchair. The

J. A. E. Spaan ( $\square)$

Department of Biomedical Engineering and Physics,

Academic Medical Center, University of Amsterdam,

Amsterdam, The Netherlands

e-mail: j.a.spaan@amc.uva.nl feasibility was tested on real patient data. It is the combination of state of the art numerical modeling and clinical verification that makes this manuscript to a nice example of quality biomedical engineering publication. The reviewers acknowledged that the paper reports on important work in the translation of engineering to clinical science in pressure ulcer prevention.

Several papers related to the cardiovascular system were on the short list. Cardiac resynchronization therapy is important in preventing failure of the heart and for this the position of the coronary sinus, CS, lead is important. Corsi et al. [1] developed a method for quantifying CS lead position in the 3D domain throughout the cardiac cycle at implant and at follow-up using chest fluoroscopy. Transesophageal left ventricular electrogram-recording and temporary pacing was developed to improve patient selection for cardiac resynchronization by Heinke et al. [6]. The cardiorespiratory synchrogram is a stroboscopic-based graphical tool for evaluating phase-locking between cardiac and respiratory oscillators. This method was improved by including an adaptive delay in the cardiac oscillator by Kabir et al. [9]. Sola et al. [16] presented first experimental evidence that electrical impedance tomography is capable of measuring pressure pulses directly within the descending aorta and thereby opens the way to an unsupervised method for arterial blood pressure measurement. Westerhof et al. [19] reconstructed aortic pressure from 24-h intra-brachial and simultaneously obtained non-invasive finger pressure in hypertensive and normotensive patients. From these registrations, it was concluded that cardiac oxygen supply is compromised during the night in hypertensive patients.

\footnotetext{
${ }^{1}$ http://www.ipem.org.uk/ipem_public.

${ }^{2}$ http://ifmbe.org/.
} 
The other papers in the short list were all focused on very important issues. Microdialysis can be used in parallel to deep brain stimulation (DBS) to relate biochemical changes to the clinical outcome. Diczfalusy et al. [2] developed a finite element method to predict the tissue volume of influence and to visualize this volume in relation to patient anatomy. The visual system offers a unique possibility of experimental manipulation of stimulus sizerelated increases of the spatial extent of cortical activation. This was studied using magnetoencephalography by Golubic et al. [4].

The last but not least paper on the short list appeared as original article in the special issue 'Trends in rehabilitation robotics' [3]. A new method was proposed for providing assistance during cyclical movements by Ronsse et al. [15]. This method is trajectory-free in the sense that it provides assistance irrespective of the performed movement and requires no other sensing than the assisting robot's own encoders.

This will be the last time that as editor in chief I have the pleasure to announce the yearly Nightingale Prize. The topics that are covered by the winning papers over the last 6 years demonstrate that MBEC aims to serve the Biomedical Engineering community at large. This is also demonstrated by the countries where the winners came from Denmark [11], Australia [7], Taiwan China [8], Canada [10], Spain [5] and now Israel [13]. The editors see this as a healthy sign that the journal serves as a medium for state of the art research in traditional and emerging fields as it develops over the many countries that are also represented in the IFMBE.

On behalf of the editors, IPEM and IFMBE, I wholeheartedly congratulate the winner of the Nightingale Prize 2011. However, also the other top scorers should be congratulated with their excellent contributions.

As always, we are grateful to IPEM and IFMBE for maintaining the Alfred Nightingale Prize.

\section{References}

1. Corsi C, Tomasi C, Turco D, Margheri M, Lamberti C, Severi S (2011) 3D dynamic position assessment of the coronary sinus lead in cardiac resynchronization therapy. Med Biol Eng Comput 49:901-908. doi:10.1007/s11517-011-0794-3

2. Diczfalusy E, Zsigmond P, Dizdar N, Kullman A, Loyd D, Wardell K (2011) A model for simulation and patient-specific visualization of the tissue volume of influence during brain microdialysis. Med Biol Eng Comput 49:1459-1469. doi: 10.1007/s11517-011-0841-0

3. Garcia N, Sabater-Navarro JM, Gugliemeli E, Casals A (2011) Trends in rehabilitation robotics. Med Biol Eng Comput 49:1089-1091. doi:10.1007/s11517-011-0836-x
4. Golubic SJ, Susac A, Grilj V, Ranken D, Huonker R, Haueisen J, Supek S (2011) Size matters: Meg empirical and simulation study on source localization of the earliest visual activity in the occipital cortex. Med Biol Eng Comput 49:545-554. doi: 10.1007/s11517-011-0764-9

5. Guerrero-Mosquera C, Trigueros AM, Franco JI, Navia-Vazquez A (2010) New feature extraction approach for epileptic EEG signal detection using time-frequency distributions. Med Biol Eng Comput 48:321-330. doi:10.1007/s11517-010-0590-5

6. Heinke M, Ismer B, Kuhnert H, Figulla HR (2011) Transesophageal left ventricular electrogram-recording and temporary pacing to improve patient selection for cardiac resynchronization. Med Biol Eng Comput 49:851-858. doi:10.1007/s11517-0110767-6

7. Hou J, Shi W, Li G, Zhou W (2007) An effective non-parametric method for globally clustering genes from expression profiles. Med Biol Eng Comput 45:1175-1185. doi:10.1007/s11517007-0271-1

8. Huang HH, Lee YH, Chan HL, Wang YP, Huang CH, Fan SZ (2008) Using a short-term parameter of heart rate variability to distinguish awake from isoflurane anesthetic states. Med Biol Eng Comput 46:977-984. doi:10.1007/s11517-008-0342-y

9. Kabir MM, Saint DA, Nalivaiko E, Abbott D, Baumert M (2011) Time delay correction of the synchrogram for optimized detection of cardiorespiratory coordination. Med Biol Eng Comput 49:1249-1259. doi:10.1007/s11517-011-0822-3

10. Li LP, Cheung JT, Herzog W (2009) Three-dimensional fibrilreinforced finite element model of articular cartilage. Med Biol Eng Comput 47:607-615. doi:10.1007/s11517-009-0469-5

11. Nielsen M, Kamavuako EN, Andersen MM, Lucas MF, Farina D (2006) Optimal wavelets for biomedical signal compression. Med Biol Eng Comput 44:561-568. doi:10.1007/s11517-006-0062-0

12. Opthof T (2011) Differences in citation frequency of clinical and basic science papers in cardiovascular research. Med Biol Eng Comput 49:613-621. doi:10.1007/s11517-011-0783-6

13. Portnoy S, Vuillerme N, Payan Y, Gefen A (2011) Clinically oriented real-time monitoring of the individual's risk for deep tissue injury. Med Biol Eng Comput 49:473-483. doi:10.1007/ s11517-011-0754-y

14. Rémond A (1963) Dr. A. Nightingale, 1923-1963. Med Biol Eng Comput 1:159-160

15. Ronsse R, Lenzi T, Vitiello N, Koopman B, van Asseldonk E, De Rossi SM, van den Kieboom J, van der Kooij H, Carrozza MC, Ijspeert AJ (2011) Oscillator-based assistance of cyclical movements: model-based and model-free approaches. Med Biol Eng Comput 49:1173-1185. doi:10.1007/s11517-011-0816-1

16. Sola J, Adler A, Santos A, Tusman G, Sipmann FS, Bohm SH (2011) Non-invasive monitoring of central blood pressure by electrical impedance tomography: first experimental evidence. Med Biol Eng Comput 49:409-415. doi:10.1007/s11517-0110753-z

17. Spaan JA (2007) The nightingale prize for the best scientific paper published in MBEC 2006. Med Biol Eng Comput 45:1161-1162. doi:10.1007/s11517-007-0287-6

18. Spaan JA (2009) Biomedical engineering and bibliometric indices for scientific quality. Med. Biol. Eng Comput 47:1219-1220

19. Westerhof BE, van Lieshout JJ, Parati G, van Montfrans GA, Guelen I, Spaan JA, Westerhof N, Karemaker JM, Bos WJ (2011) Cardiac oxygen supply is compromised during the night in hypertensive patients. Med Biol Eng Comput 49:1073-1081. doi: 10.1007/s11517-011-0810-7 